\title{
Optimizing Woven Curtain Fabric Defect Classification using Image Processing with Artificial Neural Network Method at PT Buana Intan Gemilang
}

\author{
Shadika ${ }^{1,}$, Tatang Mulyana ${ }^{2}$, and Meldi Rendra $^{3}$ \\ 1,2,3 Telkom University, Industrial Engineering, Bandung, West Java, Indonesia
}

\begin{abstract}
The textile industry is one of the industries that provide high export value by occupying the third position in Indonesia. The process of inspection on traditional textile enterprises by relying on human vision that takes an average scanning time of 19.87 seconds. Each roll of cloth should be inspected twice to avoid missed defects. This inspection process causes the buildup at the inspection station. This study proposes the automation of inspection systems using the Artificial Neural Network (ANN). The input for ANN comes from GLCM extraction. The automation system on the defect inspection resulted in a detection time of 0.56 seconds. The degree of accuracy gained in classifying the three types of defects is $88.7 \%$. Implementing an automated inspection system results in faster processing time.
\end{abstract}

\section{Introduction}

Textile industry is one of the industrial sectors that ranks third largest exporter of export value that can increase foreign exchange. In order to produce products that conform to standards and quality based on consumer demand, it takes inspection process on the fabric. Inspection process at the company at this time is still done manually using the human eye with the help of lighting in the form of lights. After calculating the processing time to the manual inspection process obtained the average scanning time of 19.7 seconds. In addition, the limitations of human vision and human error affect greatly in the process of manual inspection, such as the defects that are missed when the fabric is inspected. Based on the company's production data, the volume of production and inspection volume are not balanced, since the total fabric produced is not entirely inspected on time.

This has an impact on the unfulfilled consumer demand within the specified time. This research designs a proposal system in the form of an integrated automation system that aims to optimize the inspection process with the help of image processing. The purpose of this research is to be able to classify defects in fabric using artificial neural network method by substituting the function of human vision into digital image processing. The use of artificial

*Corresponding author: shadikawanef@gmail.com 
neural network methods is done to reduce the inspection time and increase the accuracy level in classifying defects.

\section{Basic Theory}

Quality is an important factor affecting products and services. The higher the quality of a cloth the less the defects are in the fabric and vice versa. Improving quality is a major factor in achieving business success, growth and enhancing the competitiveness of enterprises [17]. To determine the type of defects in the fabric based on Indonesian national standard (SNI) 08-0277-1989 consisting of 17 types of defects as contained in Table 1. The type of fabric defects observed generally found in textile companies based on SNI 08-0277-1989 data can be seen in Table 2 .

Table 1. Types of defects on fabrics based on SNI 08-0277-1989

\begin{tabular}{|c|c|c|}
\hline & Defect Type & Defect Definition \\
\hline 1 & Nep & Nep \\
\hline 2 & Sub & Yarn twisted, slab broken yarn, dirt plaster, knot yarn \\
\hline 3 & Uneven yarn & Large yarn, small yarn \\
\hline 4 & Broken yarn & Broken warp, broken feed \\
\hline 5 & Tight yarn/saggy & Wrinkled woven fabric, arches \\
\hline 6 & Line fold & Folded fabric \\
\hline 7 & Warp line & $\begin{array}{l}\text { Different yarn structure, comb lines, double weld, usi rapat, } \\
\text { dense meetings, rare warp, different types of fibers, large } \\
\text { yarns, small yarns. }\end{array}$ \\
\hline 8 & Feed line & $\begin{array}{l}\text { Double feed, stop mark, feed meetings, rare feed, large } \\
\text { yarns, small yarn. }\end{array}$ \\
\hline 9 & Incorrect pattern & $\begin{array}{l}\text { Pattern defects, incorrect stamped shapes, wrong webbing, } \\
\text { stamped marks, wrong color coractenun }\end{array}$ \\
\hline 10 & Bare & $\begin{array}{l}\text { Different thread structures, different types of fibers, feed } \\
\text { meetings, rare feed }\end{array}$ \\
\hline 11 & Stripped & Unevenness of color, color difference \\
\hline 12 & Tear & Hole, tear \\
\hline 13 & Unfinished yarn & Skipped yarn \\
\hline 14 & Stains & Rust stains, color stains \\
\hline 15 & Wide defects & \\
\hline 16 & Feed bias & Feed bias include the curved feed \\
\hline 17 & Flaw defects & \\
\hline
\end{tabular}

Artificial Neural Network (ANN) is one of the branches of Artificial Intelligence. ANN is an information processing system that has characteristics resembling a biological neural network. Neural networks are inspired by human biology and consist of several processing units called nerves. ANN can be interpreted as information processing that implies the input vector data and the output vector data.

Table 2. Similarity of type of fabric defect based on SNI and observation result

\begin{tabular}{|c|c|c|}
\hline \multirow{2}{*}{ No } & \multicolumn{2}{|c|}{ Defect Similarity } \\
\cline { 2 - 3 } & SNI & Observation Result \\
\hline 1 & Nep & Hairy Feed \\
\hline 2 & Slab & Brittle Feed \\
\hline
\end{tabular}




\begin{tabular}{|c|c|c|}
\hline 3 & Broken Yarn & Broken Warp \\
\hline 4 & Tight Yarn & Tight Wrap \\
\hline 5 & Warp Line & Comb Defects \\
\hline 6 & Incorrect Pattern & Broken Card \\
\hline 7 & Unfinished Yarn & Plotting \\
\hline
\end{tabular}

The most significant advantage of ANN is the mapping function of the results can be determined through the training vector, as ANN can perform the learning process from the provided training data. There are two types of Artificial Neural Network architecture commonly used, namely: Single-Layer Networks and Multilayer Networks. Single - layer networks are used to classify and work well when classes are linearly separated. During the training phase, the input and output pairs are used to train the network. Figure 1 shows the inputs $(x 1, x 2 \ldots x n)$ and output $(y 1, y 2, y 3 \ldots y m)$. Using the input vector, the actual output is compared to the desired output, and the error between the actual output and the desired output is used to update the load.

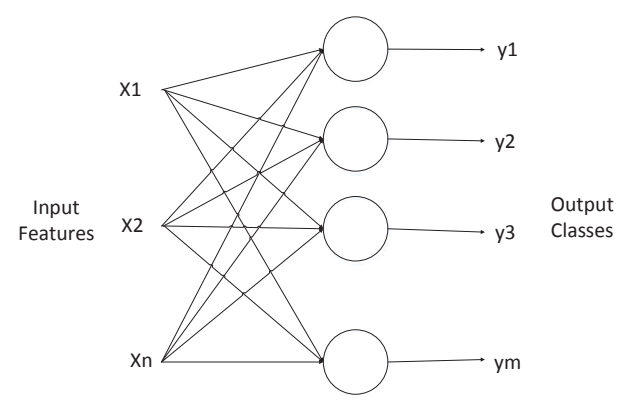

Fig 1. Single-Layer Networks

To make more complex decisions, a multilayer perceptron model is required. The architecture of the multilayer network in Figure 2 shows three types of layers: the input layer, the hidden layer, and the output layer. Multilayer network can be trained by using back propagation learning algorithm. The actual output vector is compared with the desired output vector, if there is no change then no load is changed, in contrast if any then the weight is updated [8$11]$.

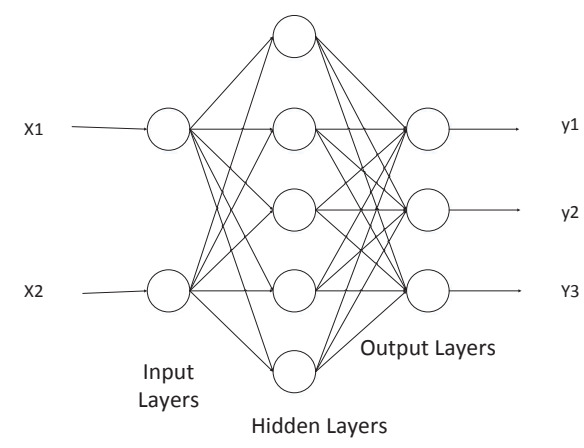

Fig. 2. Multilayer Networks 


\section{Methodology}

To get the automated fabric defect classification using neural network some steps are needed. The step can be seen at Figure 3. First is capturing the defect image using camera, the camera that used in this research is webcam logitech C525. This research capture 30 data for each defect and 30 data for each normal fabric.After captured the fabric, then the captured image must be converted to grayscale image to make the defect classification process faster. Then the grayscale image is extracted using GLCM feature extraction as input for neural network. Next is train the network using the result of extraction feature. On this research the input is 12 factors of GLCM and the hidden layer that used is 20 hidden layer. The result then will be tested using the new data from defective fabric to make sure the system can detect the defect.

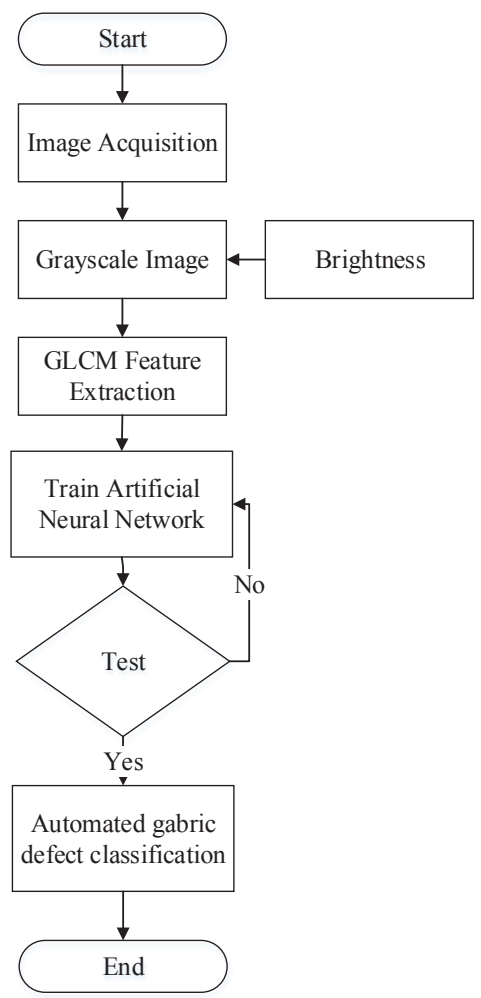

Fig. 3. Flowchart artificial neural network to obtain data

\section{Results and Discussion}

Extraction is done using Graphical User Interface (GUI) as Figure 5. The extraction results are used as ANN input. The amount of data used is as much as 120 data for training on ANN. The results of training data in the form of vectors, for defective spark plugs in the form of 1 000 , defective feed 0000 , oil defects 0001 , and normal 0010 . The accuracy of ANN training can be seen in Figure 6. Accuracy ANN training is $95.8 \%$, where in all confusion matrix there are five data that are in wrong class. 


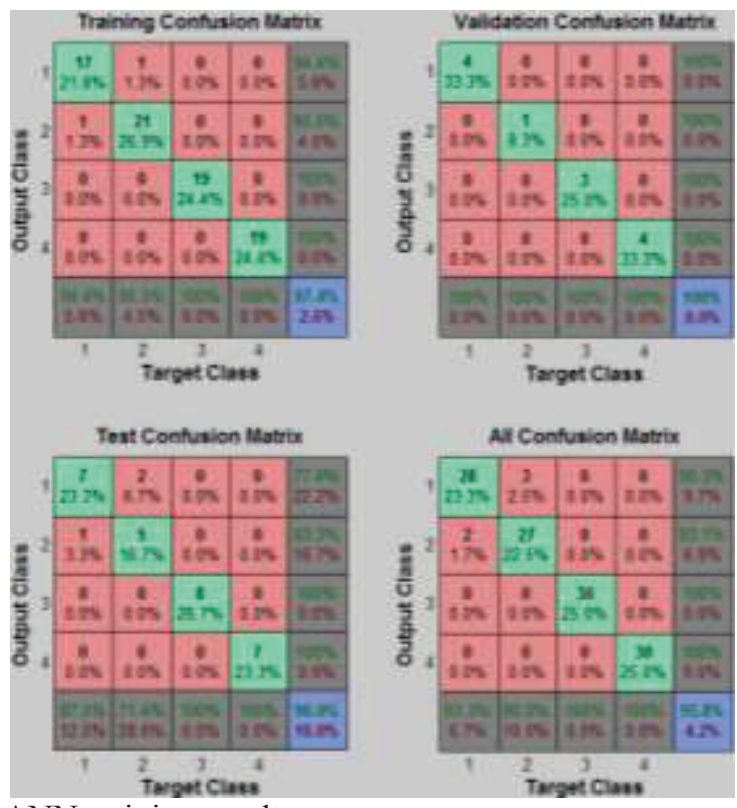

Fig.4. Accuracy of ANN training results

Furthermore, the results of the training will be the tested data as much as 80 data that is 20 defective warp, 20 defects of empty feed, 20 oil defects, and 20 normal. The result of classification test using ANN offline can be seen in Table 3. Accuracy is obtained by calculating using the following formula.

$$
\text { Accuracy }=(\text { Amount of data true }) /(\text { Total data count }) \times 100 \%
$$

Based on the offline classification results there are three incorrect data on warp defect and four incorrect data on empty feed defects. From the data, the accuracy of offline system to classified the defect on the fabric is $91 \%$.

Table 3. Offline defect classification results

\begin{tabular}{|l|r|l|r|r|}
\hline Input Type & Warp Defect & $\begin{array}{l}\text { Empty Feed } \\
\text { Defect }\end{array}$ & Normal & Oil Defect \\
\hline Warp Defect & 17 & 3 & 0 & 0 \\
\hline Empty Feed Defect & 4 & 16 & 0 & 0 \\
\hline Normal & 0 & 0 & 20 & 0 \\
\hline Oil Defect & 0 & 0 & 0 & 20 \\
\hline
\end{tabular}

After the inspection process, the processing time to classify three types of offline defects in the fabric can be seen in Table 4 . The average processing time obtained to identify 80 types of defects is for 0.73 seconds. 
Table 4. Offline classification time defects

\begin{tabular}{|c|c|c|c|c|c|c|c|}
\hline $\begin{array}{c}\text { Data } \\
\text { Number }\end{array}$ & $\begin{array}{c}\text { Process } \\
\text { Time }\end{array}$ & $\begin{array}{c}\text { Data } \\
\text { Number }\end{array}$ & $\begin{array}{c}\text { Process } \\
\text { Time }\end{array}$ & $\begin{array}{c}\text { Data } \\
\text { Number }\end{array}$ & $\begin{array}{c}\text { Process } \\
\text { Time }\end{array}$ & $\begin{array}{c}\text { Data } \\
\text { Number }\end{array}$ & $\begin{array}{c}\text { Process } \\
\text { Time }\end{array}$ \\
\hline 1 & 0.770076 & 21 & 0.621023 & 41 & 0.535614 & 61 & 0.269596 \\
\hline 2 & 0.592154 & 22 & 0.735082 & 42 & 0.524071 & 62 & 0.425395 \\
\hline 3 & 0.571321 & 23 & 0.644239 & 43 & 0.528035 & 63 & 0.444889 \\
\hline 4 & 0.646883 & 24 & 0.526157 & 44 & 0.572965 & 64 & 0.446793 \\
\hline 5 & 0.576134 & 25 & 0.598328 & 45 & 0.641985 & 65 & 0.517335 \\
\hline 6 & 0.541896 & 26 & 0.626834 & 46 & 0.620484 & 66 & 0.552104 \\
\hline 7 & 0.626375 & 27 & 0.61664 & 47 & 0.642352 & 67 & 0.461299 \\
\hline 8 & 0.570773 & 28 & 0.569393 & 48 & 0.630881 & 68 & 0.517712 \\
\hline 9 & 0.286475 & 29 & 0.534994 & 49 & 0.600921 & 69 & 0.535475 \\
\hline 10 & 0.334813 & 30 & 0.54379 & 50 & 0.637243 & 70 & 0.535781 \\
\hline 11 & 0.530931 & 31 & 0.631401 & 51 & 0.581212 & 71 & 0.518743 \\
\hline 12 & 0.299761 & 32 & 0.717383 & 52 & 0.653937 & 72 & 0.522677 \\
\hline 13 & 0.575409 & 33 & 0.619605 & 53 & 0.587051 & 73 & 0.518001 \\
\hline 14 & 0.340483 & 34 & 0.596116 & 54 & 0.638098 & 74 & 0.469349 \\
\hline 15 & 0.516364 & 35 & 0.618333 & 55 & 0.582841 & 75 & 0.472082 \\
\hline 16 & 0.651765 & 36 & 0.616771 & 56 & 0.566419 & 76 & 0.451548 \\
\hline 17 & 0.609998 & 37 & 0.551801 & 57 & 0.631268 & 77 & 0.578512 \\
\hline 18 & 0.743218 & 38 & 0.577327 & 58 & 0.652896 & 78 & 0.536244 \\
\hline 19 & 0.653092 & 39 & 0.659496 & 59 & 0.546835 & 79 & 0.516837 \\
\hline 20 & 13.4025 & 40 & 0.696695 & 60 & 0.553047 & 80 & 0.438055 \\
\hline
\end{tabular}

Furthermore, the results of the real-time test will be tested data as much as 80 data that is 20 defective warp defect, 20 defects of empty feed, 20 oil defects, and 20 normal. The result of classification test using ANN offline can be seen in Table 5. Based on the result of real time classification there is one wrong data on the defect of breaks and eight wrong data on empty feed defect. Accuracy result obtained is equal to $88.75 \%$.

Table 5. Results of real time defect classification

\begin{tabular}{|c|c|c|c|c|}
\hline Input Type & Warp Defect & $\begin{array}{l}\text { Empty Feed } \\
\text { Defect }\end{array}$ & Normal & $\begin{array}{l}\text { Oil } \\
\text { Defect }\end{array}$ \\
\hline Warp Defect & 19 & 0 & 1 & 0 \\
\hline Empty Feed Defect & 8 & 12 & 0 & 0 \\
\hline Normal & 0 & 0 & 20 & 0 \\
\hline Oil Defect & 0 & 0 & 0 & 20 \\
\hline
\end{tabular}


After the inspection process, the process time to classify the three types of defects in real time on the fabric can be seen in Table 6. After testing of 80 data obtained average time classification process defects in real time for 0.56 seconds

Table 6. Timing of real time classification process defects

\begin{tabular}{|c|c|c|c|c|c|c|c|}
\hline $\begin{array}{c}\text { Data } \\
\text { Number }\end{array}$ & $\begin{array}{c}\text { Process } \\
\text { Time }\end{array}$ & $\begin{array}{c}\text { Data } \\
\text { Number }\end{array}$ & $\begin{array}{c}\text { Process } \\
\text { Time }\end{array}$ & $\begin{array}{c}\text { Data } \\
\text { Number }\end{array}$ & $\begin{array}{c}\text { Process } \\
\text { Time }\end{array}$ & $\begin{array}{c}\text { Data } \\
\text { Number }\end{array}$ & $\begin{array}{c}\text { Process } \\
\text { Time }\end{array}$ \\
\hline 1 & 0.582776 & 21 & 7.4924 & 41 & 0.289456 & 61 & 0.304845 \\
\hline 2 & 0.54779 & 22 & 0.736126 & 42 & 0.2976 & 62 & 0.295765 \\
\hline 3 & 0.565936 & 23 & 0.632174 & 43 & 0.301907 & 63 & 0.279409 \\
\hline 4 & 0.552999 & 24 & 0.633404 & 44 & 0.280222 & 64 & 0.293552 \\
\hline 5 & 0.557814 & 25 & 0.54855 & 45 & 0.294041 & 65 & 0.270983 \\
\hline 6 & 0.623224 & 26 & 0.635446 & 46 & 0.286486 & 66 & 0.289948 \\
\hline 7 & 0.59373 & 27 & 0.694331 & 47 & 0.286644 & 67 & 0.282137 \\
\hline 8 & 0.631674 & 28 & 0.647753 & 48 & 0.276272 & 68 & 0.276991 \\
\hline 9 & 0.610841 & 29 & 2.96714 & 49 & 0.287542 & 69 & 0.309945 \\
\hline 10 & 0.524721 & 30 & 0.620036 & 50 & 0.279349 & 70 & 0.270983 \\
\hline 11 & 0.576364 & 31 & 0.657134 & 51 & 0.281802 & 71 & 0.281802 \\
\hline 12 & 0.598072 & 32 & 0.697748 & 52 & 0.284347 & 72 & 0.284347 \\
\hline 13 & 0.472274 & 33 & 0.7457 & 53 & 0.305232 & 73 & 0.305232 \\
\hline 14 & 0.588562 & 34 & 0.559747 & 54 & 0.284995 & 74 & 0.291053 \\
\hline 15 & 0.561275 & 35 & 0.517545 & 55 & 0.294033 & 75 & 0.301907 \\
\hline 16 & 0.56842 & 36 & 0.521062 & 56 & 0.285294 & 76 & 0.280222 \\
\hline 17 & 0.660343 & 37 & 0.623472 & 57 & 0.272616 & 77 & 0.294041 \\
\hline 18 & 0.587955 & 38 & 0.68808 & 58 & 0.270013 & 78 & 0.286486 \\
\hline 19 & 0.566684 & 39 & 0.519799 & 59 & 0.273119 & 79 & 0.293087 \\
\hline 20 & 0.548564 & 40 & 0.51098 & 60 & 0.291053 & 80 & 0.275745 \\
\hline
\end{tabular}

Results Recap data from MATLAB which is connected with excel software can be seen in Table 7. From the data recap, it can be known that the average data recap time for 80 data is 2.96. The recap time of the proposed data is faster than the time of recap of the existing data.

Table 7. Results of recapitulation of defect classification data

\begin{tabular}{|c|c|c|c|c|c|c|c|}
\hline $\begin{array}{c}\text { Data } \\
\text { Number }\end{array}$ & $\begin{array}{c}\text { Process } \\
\text { Time }\end{array}$ & $\begin{array}{c}\text { Data } \\
\text { Number }\end{array}$ & $\begin{array}{c}\text { Process } \\
\text { Time }\end{array}$ & $\begin{array}{c}\text { Data } \\
\text { Number }\end{array}$ & $\begin{array}{c}\text { Process } \\
\text { Time }\end{array}$ & $\begin{array}{c}\text { Data } \\
\text { Number }\end{array}$ & $\begin{array}{c}\text { Process } \\
\text { Time }\end{array}$ \\
\hline 1 & 2.84671 & 21 & 2.78742 & 41 & 2.72373 & 61 & 3.08017 \\
\hline 2 & 2.97526 & 22 & 2.82463 & 42 & 2.74481 & 62 & 3.16672 \\
\hline 3 & 3.88056 & 23 & 3.07639 & 43 & 2.82579 & 63 & 3.1096 \\
\hline 4 & 3.05133 & 24 & 2.89045 & 44 & 3.07321 & 64 & 2.7942 \\
\hline 5 & 2.83511 & 25 & 2.93238 & 45 & 2.77318 & 65 & 3.05807 \\
\hline 6 & 3.08693 & 26 & 2.80888 & 46 & 2.83453 & 66 & 3.05117 \\
\hline 7 & 3.17767 & 27 & 2.99983 & 47 & 2.85975 & 67 & 3.20491 \\
\hline 8 & 2.89033 & 28 & 2.81963 & 48 & 3.08696 & 68 & 3.0247 \\
\hline 9 & 3.00807 & 29 & 2.96695 & 49 & 2.92583 & 69 & 2.93309 \\
\hline 10 & 3.06618 & 30 & 2.97499 & 50 & 2.77245 & 70 & 2.74482 \\
\hline 11 & 3.11074 & 31 & 2.84647 & 51 & 3.13556 & 71 & 3.06182 \\
\hline
\end{tabular}




\begin{tabular}{|c|c|c|c|c|c|c|c|}
\hline 12 & 3.04461 & 32 & 2.90035 & 52 & 2.91712 & 72 & 2.96934 \\
\hline 13 & 2.78062 & 33 & 3.21018 & 53 & 2.85838 & 73 & 3.0847 \\
\hline
\end{tabular}

Table 7. Results of recapitulation of defect classification data (continued)

\begin{tabular}{|c|c|c|c|c|c|c|c|}
\hline $\begin{array}{c}\text { Data } \\
\text { Number }\end{array}$ & $\begin{array}{c}\text { Process } \\
\text { Time }\end{array}$ & $\begin{array}{c}\text { Data } \\
\text { Number }\end{array}$ & $\begin{array}{c}\text { Process } \\
\text { Time }\end{array}$ & $\begin{array}{c}\text { Data } \\
\text { Number }\end{array}$ & $\begin{array}{c}\text { Process } \\
\text { Time }\end{array}$ & $\begin{array}{c}\text { Data } \\
\text { Number }\end{array}$ & $\begin{array}{c}\text { Process } \\
\text { Time }\end{array}$ \\
\hline 14 & 2.81724 & 34 & 2.80832 & 54 & 3.03216 & 74 & 3.06013 \\
\hline 15 & 2.84362 & 35 & 2.72155 & 55 & 2.99249 & 75 & 3.13935 \\
\hline 16 & 3.19836 & 36 & 3.08313 & 56 & 3.09187 & 76 & 3.02288 \\
\hline 17 & 2.87577 & 37 & 2.79001 & 57 & 2.79276 & 77 & 2.75014 \\
\hline 18 & 2.95698 & 38 & 3.05507 & 58 & 2.80411 & 78 & 2.89962 \\
\hline 19 & 3.01999 & 39 & 2.83755 & 59 & 2.77501 & 79 & 2.74452 \\
\hline 20 & 3.02631 & 40 & 2.89411 & 60 & 3.09436 & 80 & 2.92068 \\
\hline
\end{tabular}

Based on the results of the research, the comparison of the existing manual process and the time of the proposed process can be seen in Table 8 . In Table 8 it can be seen that scanning defects are faster than the existing process of 0.56 seconds, as well as the recap of the proposed defect faster than the existing process time is 2.96 seconds. The total process time of the proposed system is 3.5 seconds, 29.8 seconds faster than the existing system with a total processing time of 33.57 seconds.

Table 8. Comparison of total results of proposed and existing process time

\begin{tabular}{|c|c|c|c|}
\hline No & Activity & Existing (second) & Automated (second) \\
\hline 1 & Defect Scanning & 19.87 & 0.56 \\
\hline 2 & Defect Recap & 13.5 & 2.97 \\
\hline \multicolumn{2}{r|}{ Total (second) } & 33.37 & 3.52 \\
\hline
\end{tabular}

\section{Conclusion}

The manual inspection process has several drawbacks so that an automated inspection process that minimizes manual inspection is needed. One way to use is to use image processing to improve process accuracy and reduce the average time of the inspection process. In this research used artificial neural network method with GLCM extraction feature and processed by using MATLAB software. In the extraction feature used 12 parameters to get the best results on the process of classification of fabric defects. The proposed system is capable of generating an overall accuracy of $88.75 \%$ and an average processing time of 0.56 seconds. The proposed system is capable of producing faster processing time than the existing time. The timing of the proposal is 29.8 seconds faster, so the use of defect classification with ANN can be applied to speed up the inspection process time.

\section{References}

[1] D.C.Montgomery. Introduction to Statistical Quality Control, Sixth Edition (John Wiley \& Sons, Inc, United States of America, 2009) 
[2] H Rachmat, T Mulyana, SH Hasan, MR bin Ibrahim, Design Selection of In-UVAT Using MATLAB Fuzzy Logic Toolbox, International Conference on Soft Computing and Data Mining, 538-545, (2017).

[3] E. Kurniawan, B. Rahmat, T. Mulyana and J. Alhilman, "Data analysis of Li-Ion and lead acid batteries discharge parameters with Simulink-MATLAB," 2016 4th International Conference on Information and Communication Technology (ICoICT). 1-5 (2017)

[4] H. Rachmat and T. Mulyana, "Website design of EMS-SCADA for AC usage on a building," 2015 3rd International Conference on Information and Communication Technology (ICoICT), 17-22 (2015)

[5] R. A. Anugraha and T. Mulyana, "Monitoring and controlling of EMS-SCADA via SMS gateway," 2015 3rd International Conference on Information and Communication Technology (ICoICT). 613-617 (2015)

[6] T. Mulyana, J. Alhilman and E. Kurniawan, "Data analysis using system identification toolbox of heat exchanger process control training system," 2016 th International Conference on Information and Communication Technology (ICoICT). 1-6.( 2016)

[7] M. Tatang. NNARX model structure for the purposes of controller design and optimization of heat exchanger process control training system operation. In: AIP Conference Proceedings. 020040. (2017)

[8] P. Banumathi, T. S. Sree, V.Priya. Artificial Intelligence Techniques in Textile Fabric.4, 6 (2015)

[9] M.Risaldi, Purwanto, H.Himawan. Classification of Coconut Wood Using Neural Network Backpropagation Algorithm.10, 10 (2014)

[10] A. Kadir, A. \& A. Susanto, Theory and Applications of Image Processing. (Andi Publisher, Yogyakarta, 2013)

[11] A.D. Kulkarni, Computer Vision and Fuzzy Neural Systems (Prentice Hall PTR, New Jersey, 2001) 